\title{
Veterinary
}

\section{Is there a link between treatments with exogenous corticosteroids and dog behaviour problems?}

\begin{tabular}{|c|c|}
\hline Journal: & Veterinary Record \\
\hline Manuscript ID & vetrec-2016-103768.R1 \\
\hline Article Type: & Paper \\
\hline Date Submitted by the Author: & 20-Jun-2016 \\
\hline Complete List of Authors: & $\begin{array}{l}\text { Notari, Lorella } \\
\text { Burman, Oliver; University of Lincoln, School of Life Sciences } \\
\text { Mills, Daniel; University of Lincoln, Department of Biological Sciences }\end{array}$ \\
\hline Abstract: & $\begin{array}{l}\text { Possible side effects of exogenous corticosteroids have been described in } \\
\text { both humans and laboratory animals with recent studies highlightig this } \\
\text { issue in dogs. In this paper the behaviour of } 345 \text { dogs drawn from the } \\
\text { behavioural caseload of a behaviour clinic based in the north of Italy } \\
\text { between February } 2012 \text { and November } 2014 \text {, were analysed. Possible } \\
\text { relationships between dogs that received treatment with corticosteroids } \\
\text { versus dogs that received a treatment with drugs other than corticosteroids } \\
\text { and positive or negative affective states, aggression towards people, other } \\
\text { behaviour problems apart from aggression, occurrence of severe bites and } \\
\text { prescription of psychoactive drugs were initially assessed using a Pearson's } \\
\text { Chi Squared test. } \\
\text { Regression analysis was then performed in order to evaluate the best } \\
\text { predictors of the investigated items. The goal of this retrospective survey } \\
\text { was to investigate possible relationships between the affective states } \\
\text { associated with the behavioural complaint of dogs and their previous } \\
\text { history of treatment with corticosteroids drugs. Results showed that a } \\
\text { history of corticosteroid treatment was a significant predictor of a range of } \\
\text { behaviour problems associated with negative affective state, but this result } \\
\text { may be confounded by age related effects. }\end{array}$ \\
\hline
\end{tabular}

\section{SCHOLARONE"}

Manuscripts 
2 behaviour problems?

\section{Notari, O. Burman and D. S. Mills}

Author affiliation: Animal Behaviour, Cognition and Welfare Group, School of Life Sciences, Joseph Banks Laboratories, University of Lincoln, Lincoln LN6 7DL, UK

Corresponding author: Lorella Notari lorellanotari@lorellanotari.it

\section{Abstract}

Possible side effects of exogenous corticosteroids have been described in both humans and laboratory animals with recent studies highlighting this issue in dogs. In this paper the behaviour of 345 dogs drawn from the behavioural caseload of a behaviour clinic based in the north of Italy between February 2012 and November 2014, were analysed. Possible relationships between dogs that received treatment with corticosteroids versus dogs that received a treatment with drugs other than corticosteroids and positive or negative affective states, aggression towards people, other behaviour problems apart from aggression, occurrence of severe bites and prescription of psychoactive drugs were initially assessed using a Pearson's Chi Squared test. Regression analysis was then performed in order to evaluate the best predictors of the investigated items. The goal of this retrospective survey was to investigate possible relationships between the affective states associated with the behavioural complaint of dogs and their previous history of treatment with corticosteroids drugs. Results showed that a history of corticosteroid treatment was a significant predictor of a range of behaviour problems associated with negative affective state, but this result may be confounded by age related effects.

\section{Introduction.}

Psychiatric side effects of corticosteroid drugs have been reported in humans and laboratory animals (Drozdowicz and Bostwick, 2015; Mikics et al., 2007; Warrington and Bostwick, 2006) and behavioural changes related to corticosteroid treatments have also been reported by dog owners (Notari and Mills, 2011; Notari et al., 2015). Direct testing of dogs also showed that dogs on corticosteroids were less explorative compared with control dogs (Notari et al., 2015). There is a literature to indicate that corticosteroid therapies might negatively influence the behaviour of both 
1 human and non-human animals and so it is worth investigating about what proportion of dogs

2 presented for different behaviour problems have a history of treatment with corticosteroids and

3 whether corticosteroids appear to increase the risk of any complaints associated with sensitivity to

4 aversion, e.g. fears and anxieties.

5 From the human psychiatric literature, we know that the negative psychological side effects of

6

7

8

9

10 corticosteroid therapies can be more evident in patients that already have some psychiatric disturbance (Fardet et al., 2012; Kenna et al., 2011; Sirois, 2003; Ularntinon et al., 2010), But we do not know if an analogous situation occurs in non-human animals or what proportion of dogs with different types of behaviour problem previously have been given corticosteroid drugs. Such information will provide better insight into the possible behavioural side effects of these drugs, in particular in dogs predisposed to behaviour disturbance.

The use of corticosteroid drugs in veterinary practice has been investigated previously using a survey in three UK veterinary practices and a wide variation in prescribing patterns was detected. It was reported that $14.55 \%$ of dog consultations resulted in systemic glucocorticoid therapy (O’Neill et al., 2012). Despite the frequency of this practice and the large amount of literature in other species that indicates the possible influence of corticosteroid drugs on behaviour, no retrospective analysis has ever been done to investigate possible relationships between corticosteroid therapies and behavioural problems in dogs.

The retrospective analysis of cases presented in this paper, for the first time, investigates the possible implications of a history of treatment with corticosteroids in a population of dog behaviour patients. The goals were to gather information about the proportion of dogs with behaviour problems that had a history of corticosteroid therapies and to investigate possible relationships with behaviour problems and the underlying affective state associated with groups of these problems. The relationship between history of corticosteroid therapy and the prescription of psychoactive drugs was also investigated, because this might be related to the severity of behaviour problems (Dodman et al., 1996; King et al., 2000; Marder, 1991; Pineda et al., 2014).

\section{Material and methods}

\section{Sample}

The files of 345 dogs aged between 1 and 10 years that had presented for behavioural problems were selected from the dog caseload of a veterinary behavioural clinic based in the north of Italy. This age range was selected to decrease the probability that reported behaviour problems were due 
1 to management problems in puppies or health conditions due to aging in older dogs. The data were

2 collected for cases seen in the period February 2012 to November 2014 . .

3

4 5

6 Each case file was analyzed and the following items of data were extracted for the purpose of this investigation:

1. Age of dog

2. Gender and reproductive status of dog

3. Breed type divided into the number of Federation Cinologique International Group (FCI) for all the recognized breeds. Pitbull type dogs were coded as 'Pitbull', with crossbreed dogs coded as 'crossbreed'. Dog breed recognition was based on morphological features of the dogs and from owner statements.

4. Treatment and medical history of dogs treated with corticosteroid drugs

5. Treatment and medical history of dogs treated with other drugs.

6. Presence of aggression towards people

7. Types of bites (severe or not severe)

8. Behaviour problems other than aggression

9. Prescription of psychoactive drugs to address the behavioural complaint

10. Affective state (see below for details about definition of positive or negative affective state)

The source of the above information was both the Dog Behavioural History Form used in the behaviour clinic, that was completed for every dog at the time of the first consultation, and the therapist's own diagnostic and therapeutic notes.

For 'history of treatment with corticosteroids' only systemic treatments that lasted more than one week were taken into consideration, in order to avoid single treatments for emergency interventions, since the effects of longer term administration were the focus of interest. Data about treatment with corticosteroid drugs was extrapolated from the Dog Behavioural History Form completed during behavioural consultation in the section concerning the medical history of patient. The exact administered dose was not always recalled by owners and an inclusion requirement for those subjects recorded as 'received treatment with corticosteroids' was that the owner could recall the name of the product, the reason why it was prescribed and the length of the therapy in terms of more than a week or less than a week. As far as the item 'history of treatment with other drugs' (Item 5) was concerned, reported treatments were considered as for treatment with corticosteroids. 
1 Evidence of past medical problems and past treatments were provided by medical records given by

2 owners or by veterinary surgeons that referred the behavioural case.

3 As far as the item 'types of bites', bites that required medical intervention were considered as

4 'severe bites'. Negative and positive affective states were coded (see below) on the basis of the

5 responses of the owners to questions included in the Dog Behavioural History Form specifically in

6

7

8

9

10

11

12

13

14 the section entitled 'Your dog's personality' in conjunction with the evaluation of the veterinary behaviourist who held the consultation. As far as the information extracted from the Dog Behavioural History Form was concerned, owners had to answer 'yes' or 'no' to the following questions:

1. Do you consider your dog as aggressive in most situations?

2. Do you think that your dog is often or always nervous or fearful in the presence of unknown situations or stimuli (sounds, new stimuli, unknown people or dogs)?

3. Do you consider your dog largely enthusiastic and excited?

4. Do you think that your dog is sociable in general?

5. Do you consider your dog confident?

To be coded as having a positive affective state, the owner had to answer 'No' to questions one and two and 'Yes' to at least two of the last three questions. To be coded as having a negative affective state the owner had to answer 'Yes' to at least one of the first two questions. The final definition of affective state as positive or negative in connection with the type of behaviour problem was established through the behavioural consultation and based on the description of the problem behaviour and its context as well as the direct observation of the dog's behaviour in the clinical context by the behaviour clinician.

Positive affective state was attributed to dogs with problem behaviours that were most likely to be related to positive emotional reactions but perceived as problematic and/or exaggerated by their owners, for example:

- excessive play behaviour

- excessive activity such as running, digging, stealing objects

- excessive attention seeking behaviours, such as jumping on people, barking for attention Negative affective state was attributed to dogs presenting with behaviours that were more likely to be related to negative emotions such as fear, anxiety and frustration. For example:

- fear, phobia and anxiety

- avoidant or assertive displays of aggressive behaviours

- repetitive conflict behaviours 
1

2

3

4

5

6

7

8

9

10

\section{Statistical analysis}

2

3 Analysis was performed using IBM SPSS Statistic 21, with summary descriptive statistics

4 calculated initially.

5 We assessed, using the Pearson's Chi Squared test, possible associations between dogs that received 6 treatment with corticosteroids versus dogs that received a treatment with other drugs different from 7 corticosteroids and:

8 - positive or negative affective states

$9 \quad-$ aggression towards people

10 - other behaviour complaints besides aggression

11 - occurrence of severe bites

12 - prescription of psychoactive drugs

13 Regression analysis was then performed in order to hierarchically evaluate the best predictors of the 14 investigated items $(\mathrm{p}<0.05)$. 
3 From the initial sample of 345 dogs selected from the author's caseload database containing

4 completely filled in Dog Behavioural Forms, 2 dogs were excluded because of incomplete reports

5 about medical history and treatment and a final sample of 343 was used for analysis.

6 Gender and reproductive state of dogs are shown in Table 1.

7

\begin{tabular}{|l|l|l|l|}
\hline Gender and reproductive state & $\begin{array}{l}\text { Total frequency } \\
\text { n. }(\%)\end{array}$ & $\begin{array}{l}\text { Frequency (n.) (\%) } \\
\text { No cortico group }\end{array}$ & $\begin{array}{l}\text { Frequency (n.) (\%) } \\
\text { On cortico group }\end{array}$ \\
\hline intact male & $177(51.6)$ & $147(51)$ & $30(54.5)$ \\
\hline intact female & $56(16.3)$ & $49(17)$ & $7(12.7)$ \\
\hline castrated male & $35(10.2)$ & $29(10.1)$ & $6(10.9)$ \\
\hline spayed female & $75(21.9)$ & $63(21.9)$ & $12(21.8)$ \\
\hline
\end{tabular}

8 Table 1. Gender and reproductive state distribution within the sample of 343 dogs with

9 behaviour problems. No cortico group = group of dogs without a history of corticosteroid

Within the sample of 343 dogs, the age distribution of dogs is shown in Table 2. 


\begin{tabular}{||l|l|l|l|}
\hline Age & $\begin{array}{l}\text { Total frequency } \\
\text { n. (\%) }\end{array}$ & $\begin{array}{l}\text { Frequency n. (\%) } \\
\text { No cortico group }\end{array}$ & $\begin{array}{l}\text { Orequency n. (\%) } \\
\text { On cortico group }\end{array}$ \\
\hline $1-2$ years & $195(56.9)$ & $179(62.2)$ & $16(29.1)$ \\
\hline $3-4$ years & $87(25.4)$ & $70(24.3)$ & $17(30.9)$ \\
\hline $5-6$ years & $34(9.3)$ & $24(8.3)$ & $8(14.5)$ \\
\hline $7-8$ years & $26(7.6)$ & $14(4.9)$ & $12(21.8)$ \\
\hline $9-10$ years & $3(0.9)$ & $1(0.3)$ & $2(3.6)$ \\
\hline
\end{tabular}

1 Table 2. Age distribution within the sample of 343 dogs with behaviour problems. No cortico

2 group = group of dogs without a history of corticosteroid treatment; On cortico group= group

3

4

5

6 7

\begin{tabular}{|l|l|l|l|}
\hline Breed group/type & $\begin{array}{l}\text { Frequency n. } \\
(\%)\end{array}$ & $\begin{array}{l}\text { Frequency n. (\%) } \\
\text { No cortico group }\end{array}$ & $\begin{array}{l}\text { Frequency n. (\%) } \\
\text { On cortico group }\end{array}$ \\
\hline $\begin{array}{l}\text { FCI Group1 - Sheepdogs and } \\
\text { Cattledogs }\end{array}$ & $45(13.1)$ & $34(11.8)$ & $11(20.0)$ \\
\hline $\begin{array}{l}\text { FCI Group 2 - Pinscher and } \\
\text { Schnauzer - Molossoid and } \\
\text { Swiss Mountain and Cattledogs }\end{array}$ & $43(12.5)$ & $32(11.1)$ & $11(20.0)$ \\
\hline $\begin{array}{l}\text { FCI Group 3 - Terrier } \\
\text { FCI Group 4 - Dachshunds }\end{array}$ & $8(2.3)$ & $6(2.1)$ & \\
\hline $\begin{array}{l}\text { FCI Group 5 - Spitz and } \\
\text { primitive types }\end{array}$ & $10(2.9)$ & $10(3.5)$ & $6(10.9)$ \\
\hline $\begin{array}{l}\text { FCI Group 6 - Scent hounds and } \\
\text { related breeds }\end{array}$ & $8(2.3)$ & $8(2.8)$ & $(0.7)$ \\
\hline
\end{tabular}




\begin{tabular}{||l|l|l|l|}
\hline FCI Group 7 - Pointing Dogs & $9(2.6)$ & $8(2.8)$ & $1(1.8)$ \\
\hline $\begin{array}{l}\text { FCI Group 8 - Retrievers - } \\
\text { Flushing Dogs - Water Dogs }\end{array}$ & $18(5.2)$ & $13(4.5)$ & $5(9.1)$ \\
\hline $\begin{array}{l}\text { FCI Group 9 - Companion and } \\
\text { Toy Dogs }\end{array}$ & $29(8.5)$ & $25(8.7)$ & $4(7.3)$ \\
\hline FCI Group 10 - Sighthounds & $7(2.0)$ & $7(2.4)$ & $0(0)$ \\
\hline Crossbreed & & & $13(23.6)$ \\
\hline PITBULL & $126(36.7)$ & $113(39.2)$ & $2(3.6)$ \\
\hline
\end{tabular}

1 Table 3. Breed distribution within the sample of 343 dogs with behaviour problems. No cortico group = group of dogs without a history of corticosteroid treatment; On cortico

3 group= group of dogs with a history of corticosteroid treatment.

4

5 Within the sample of 343 dogs, 209 (73.8\%) had a history of treatment with drugs other than

6 corticosteroids and $55(16.0 \%)$ had a history of treatment with corticosteroid drugs. Forty-eight of

7 the 55 dogs that had a history of treatment with corticosteroids also had a history of treatment with

8 other drugs. In Table 4, the types of drug treatments other than corticosteroid in the two groups of

9 dogs with and without a history of treatment with corticosteroid drugs are shown. Drug therapies

10 have been divided into four main categories:

11 - Antibiotics and antifungal drugs

12 - Antacid drugs

13 - Non Steroidal Anti-inflammatory drugs (NSAIDs)

14 - Other drugs 
1 Table 4. Types of drug treatments other than corticosteroids used in the two groups of dogs:

2 No cortico group $=$ group of dogs without a history of corticosteroid treatment; On cortico

3 group= group of dogs with a history of corticosteroid treatment

4

5

6

7

8

9

10

\begin{tabular}{|l|l|l|}
\hline TYPE OF DRUG & $\begin{array}{l}\text { Frequency n. } \\
(\%)\end{array}$ & $\begin{array}{l}\text { Frequency n. } \\
(\%)\end{array}$ \\
& $\begin{array}{l}\text { No cortico } \\
\text { group (n.209) }\end{array}$ & $\begin{array}{l}\text { On cortico } \\
\text { Group (n.55) }\end{array}$ \\
\hline antibiotics and antifungal drugs & $162(78.3)$ & $32(66.7)$ \\
\hline antacid drugs & $18(8.7)$ & $12(25.0)$ \\
\hline NSAIDS & $17(8.2)$ & $3(6.3)$ \\
\hline others & $10(4.8)$ & $1(2.1)$ \\
\hline
\end{tabular}
(n)

Reported medical problems were divided into 5 main groups:

- Dermatological

- Orthopaedic

- Gastroenteric

- Respiratory

- Others

Whithin 'Others' were included urinary and reproductive problems, cardiovascular and hematological diseases and neurological diseases.

Medical problems reported in dogs treated with corticosteroid drugs and dogs treated with drugs other than corticosteroids are show in Table .5. 


\begin{tabular}{|l|r|r|}
\hline Medical problems & $\begin{array}{r}\text { Frequency n. (\%) } \\
\text { No Cortico } \\
\text { Group (n. 288) }\end{array}$ & $\begin{array}{r}\text { Frequency n. (\%) } \\
\text { On Cortico Group } \\
\text { (n.55) }\end{array}$ \\
\hline Dermatological & $53(18.4)$ & $36(65.5)$ \\
\hline Orthopaedic & $15(5.2)$ & $12(21.8)$ \\
\hline Gastrointestinal & $74(25.7)$ & $5(9.1)$ \\
\hline Respiratory & $54(18.8)$ & $1(1.8)$ \\
\hline Others & $33(11.5)$ & $1(1.8)$ \\
\hline No medical problems with & $79(27.2)$ & 0 \\
\hline more than 1 week therapy & & \\
\hline
\end{tabular}

Table 5. Medical problems in dogs a history of treatment with corticosteroids. No cortico group = group of dogs without a history of corticosteroid treatment; On cortico group= group of dogs with a history of corticosteroid treatment. The sum of percentages is not $100 \%$ because some subjects have multiple medical problems.

The main behavioural complaints within the sample of 343 dogs are listed in Table .6. Specific conditions were pooled into broader categories to create more suitable population sizes for analysis, as described below.

All forms of aggressive behaviour towards people with the exception of that associated with play, were grouped into a single category whether this was aggression towards family members or strangers.

Aggression towards other dogs including both aggression between dogs living together in the same family and towards unfamiliar dogs formed another class.

Predation was the complaint for just one dog and related to severe predatory behaviour towards cats. This subject was not pooled with other aggressive dogs.

All problem behaviours that were associated with distress in the absence of owners/when the dog was left alone were classed as separation problems.

Both urine marking and forms of inappropriate elimination and housetraining problems were grouped into a single class 'housesoiling problems'.

Fear of specific situations (e.g. thunderstorm, wind, unknown environments), social fear (fear of people, fear of other dogs) and fear of sounds were grouped together as phobias. 
1 Repetitive behaviours included compulsive licking, tail chasing and tail biting.

2 Excessive barking was used to refer to problematic barking in different situations.

3 Excessive play and play biting, excessive attention seeking behaviours, jumping on people,

4 destructiveness and excessive excitement in different situations were grouped as forms of

5 hyperactivity.

6 Other behaviour problems were grouped together as a single class and included cases involving a

7 tendency to run away from the property, digging and decreased activity levels.

8 Multiple behaviour problems were presented in 66.5\% (228) of the total sample of dogs. Within the

9 sample of dogs receiving treatment with corticosteroids, $51 \%$ (28) presented with multiple

10 behaviour problems.

\begin{tabular}{|l|l|}
\hline Behaviour & Total frequency n. (\%) \\
\hline Aggression towards people & $148(43.1)$ \\
\hline Aggression towards other dogs & $59(17.2)$ \\
\hline Predation & $1(0.3)$ \\
\hline Separation problems & $47(13.7)$ \\
\hline Housesoiling problems & $22(6.4)$ \\
\hline Phobias & $91(26.2)$ \\
\hline Repetitive behaviours & $11(3.2)$ \\
\hline Excessive barking & $43(12.5)$ \\
\hline Hyperactivity & $90(25.9)$ \\
\hline Other & $37(10.7)$ \\
\hline
\end{tabular}

11 Table 6. Categories of presenting complaint; the sum of percentages is not $100 \%$ because of some subjects presenting with multiple behaviour problems.

Psychoactive drugs were prescribed to $31.2 \%$ (107 dogs) of the sample. Among the 55 dogs with a history of corticosteroid treatments psychoactive drugs were prescribed in $43.6 \%$ of cases ( 24

16 dogs). Among the 290 dogs without any history of corticosteroid drugs psychoactive drugs were 17 prescribed in the $28.4 \%$ of cases ( 83 dogs).

18 The distribution of drugs used is shown in Table 7. 


\begin{tabular}{|c|c|c|c|}
\hline Prescribed drug & $\begin{array}{l}\text { Frequency n. (\%) } \\
\text { Total n. }\end{array}$ & $\begin{array}{l}\text { Frequency n. } \\
(\%) \\
\text { No cortico } \\
\text { group n. }\end{array}$ & $\begin{array}{l}\text { Frequency n. (\%) } \\
\text { On cortico group } \\
\text { n. }\end{array}$ \\
\hline Fluoxetine & $69(20.1)$ & $50(17.4)$ & $19(34.5)$ \\
\hline ||Fluvoxamine & $9(2.6)$ & $9(3.1)$ & - \\
\hline Paroxetine & $11(3.2)$ & $10(3.5)$ & $1(1.8)$ \\
\hline Selegiline & $9(2.6)$ & $8(2.8)$ & $1(1.8)$ \\
\hline Clomipramine & $8(2.3)$ & $5(1.7)$ & $3(5.5)$ \\
\hline Carbamazepine & $1(0.3)$ & $1(0.3)$ & \\
\hline
\end{tabular}

2 Table 7. Psychoactive drugs prescribed within the whole sample $(n=343)$ of dogs with

3 behaviour problems. No cortico group= dogs that did not have an history of treatment with

4

5

6

7

8

9

10

corticosteroid drugs. On cortico group $=$ dogs had a history of treatment with corticosteroid drugs.

The possible relationships between corticosteroid therapies, behaviour problems, affective states, incidence of severe bites and prescription of psychoactive drugs in the whole sample of dogs are shown in Table 8. The same relationships were investigated using the same statistical approach taking into account only dogs that had a history of medical problems that required more than one week of therapy $(\mathrm{n}=264)$ using Chi Square Tests.

Within this sample $(n=264)$, dogs with a history of corticosteroids were significantly more likely to be in negative affective states $\left(\mathrm{X}(1)=10.970, \mathrm{p}<0.001 \_\right.$), to present with aggression towards people $(X(1)=5.527, p=0,0014)$ to be prescribed psychoactive drugs $(X(1)=3.588, p=0.043)$, but significantly less likely to present problems coded as 'hyperactivity' $(X(1)=9.099, p<0.001)$.

Within dog with a history of medical problems that required more than one week of therapy (n.264) no significant relationship was found between the use of drugs other than corticosteroids and affective states, aggression towards people, prescription of psychoactive drugs and hyperactivity. 


\begin{tabular}{|l|l|l|l|l|}
\hline Patient factors & Cortico group & No cortico group & $\begin{array}{l}\text { Pearson Chi } \\
\text { square X(1) }\end{array}$ & p value \\
\cline { 2 - 4 } & n. (\%) & n. (\%) & & \\
\hline Positive affective state & 0 & $51(17.7)$ & & \\
\hline Negative affective state & $55(100.0)$ & $237(82.3)$ & 11.441 & $<0.001$ \\
\hline Aggression towards people & $31(56.4)$ & $117(40.6)$ & 4.663 & 0.023 \\
\hline Hyperactivity & $4(7.3)$ & $85(29.5)$ & 11.889 & $<0.001$ \\
\hline $\begin{array}{l}\text { Aggression towards other } \\
\text { dogs }\end{array}$ & $9(16.4)$ & $50(17.4)$ & 0.032 & 0.518 \\
\hline Separation problems & $9(16.4)$ & $38(13.2)$ & 0.330 & 0.392 \\
\hline Phobias & $13(23.6)$ & $77(26.7)$ & 0.229 & 0.384 \\
\hline Excessive barking & $5(9.1)$ & $38(13.2)$ & 0.709 & 0.276 \\
\hline History of severe bites & $16(29.1)$ & $64(22.2)$ & 1.218 & 0.175 \\
\hline $\begin{array}{l}\text { Psychoactive drug } \\
\text { prescription }\end{array}$ & $24(43.6)$ & $83(28.8)$ & 4.724 & 0.024 \\
\hline
\end{tabular}

1 Table 8. Relationship between history of treatment with corticosteroids and negative affective

2 state, reported behaviour problems, occurrence of sever bites and the prescription of

3 psychoactive drugs in the whole sample (n. 343). No cortico group = group of dogs without a

history of corticosteroid treatment; On cortico group= group of dogs with a history of corticosteroid treatment

The predictive value of age, gender and type of medical problems in the onset of positive or negative affective states was investigated in the group of dogs without a history of corticosteroid drugs but with a history of medical problems $(n=209)$ by means of binary logistic regression using forward analysis. Age was found to be the only predictor, with dogs between one and two year of age 3.167 times more likely to be in positive affective states than other ages $(B=1.153 ; p<0.01$; $\exp (B)=3.167$ C.I: $95 \%[1.44-6.96]) .82 .8 \%$ of cases could be correctly predicted in this analysis.

The role of corticosteroid treatment history, medical condition, age and gender of dogs on the main effects of aggression towards people, hyperactivity and prescription of psychoactive drugs were investigated by means of binary logistic regression using a forward analysis . 
1 The best predictor for aggression towards people was gender, with intact males 3.49 times more

2 likely to be aggressive compared toother gender groups $(B=1,250 ; \operatorname{Exp}(B)=3.489 ; p<0.01 ;$ C.I. :

$395 \%$ [2.10-5.79]) and castrated male dogs 2.8 times more likely to show aggression compared to

4 other gender groups $(B=1.049 ; \operatorname{Exp}(B)=2.828 ; p=0.011 ;$ C.I. : 95\% [1.27-6.28] $)$. Age and

5 gastrointestinal conditions showed a significant relationship with aggression towards people: dogs

6

7

8

9 between one and two years were less likely to be aggressive towards people $(B=-0.752 ; \operatorname{Exp}(B)=$ $0.471 ; \mathrm{p}<0.01$; C.I. : $95 \%[0.312-0.802)$ as were dogs with a history of gastrointestinal conditions $(B=-0.809 ; \operatorname{Exp}(B)=0.445 ; p<0.01 ;$ C.I. : $95 \%[0.250-0.792) .64 .7 \%$ of cases were correctly predicted in this analysis.

The best predictors for hyperactivity related problems were age and corticosteroid treatment: dogs between one and two year of age were 4.27 times more prone to show hyperactivity related problems compared to other ages $(B=1.193 ; \operatorname{Exp}(B)=3.298 ; p<0.01 ; C . I . ~: 95 \%[1.78-6.12])$. By contrast, dogs treated with corticosteroids were less prone to hyperactivity related problems $(\mathrm{B}=-$ $1.455 ; \operatorname{Exp}(B)=0.233 ; p<0.01 ;$ C.I. : $95 \%[0.08-0.68]$ ). $74.1 \%$ of cases were correctly predicted in this analysis.

The best predictors for the prescription of psychoactive drugs were gender and age: castrated males were 2.49 times more likely to be prescribed psychoactive drugs compared with other genders $(B=0.911 ; \operatorname{Exp}(B)=2.486 ; p=0.014 ;$ C.I.: 95\%[1.20-5.14] ). Dogs between one and two years of age were less likely to receive prescriptions for psychoactive drugs compared with other age groups $(B=-0.730 ; \operatorname{Exp}(B)=0.482 ; p<0.01 ;$ C.I. : $95 \%[0.30-0.77]) .70 .6 \%$ of cases were correctly predicted in this analysis.

\section{Discussion}

Within the sample of 343 dogs referred for behaviour problems in this particular caseload, 16\% had a history of previous treatments with corticosteroids and it should be noted that this investigation reveals only association and not necessarily causal relationships. The main finding of this retrospective case study was that history of corticosteroid treatment was significantly associated with negative affective states and a predictor of a reduced likelihood of problems of hyperactivity. A significant association between affective state and hyperactivity in the opposite direction was also 
1 found with age with dogs between one-two years of age being more likely to have problems associated with positive affective states and hyperactivity than older dogs.

3

4

Younger dogs were less likely to show aggression towards people and to be prescribed psychoactive drugs. By contrast, intact male dogs were more likely to show aggression towards people and this result is consistent with much of the previous literature data (Fatjo et al., 2007; Guy et al., 2001; Overall and Love, 2011; Overall, 1997).

A history of medical problems was not a significant predictor for behaviour problems with the exception of gastrointestinal problems that were associated with a lower tendency to show aggression towards people. No link with affective states or behaviour problems was found between the administration of drugs other than corticosteroids.

These results must be considered with some caution, but they highlight the need for further investigation of the possible links between behavioural problems related with negative affective states and the use of corticosteroids. Although it should be emphasised that a causal link has not been demonstrated, these data when considered alongside previous studies in this field (Notari and Mills, 2011; Notari et al., 2015) and the absence of data to the contrary, suggest that there might be behavioural side effects of corticosteroids. The small sample size and the differences in the two groups, with and without history of corticosteroid drug treatments, are obvious limitations as well as the possibility that the link between corticosteroid treatments and negative affects might be simply due to the fact that older dogs, who were more represented in the corticosteroid group, might also be more likely to show negatively motivated behaviours compared with younger dogs, and were over-represented in the group not receiving corticosteroids. Medical problems and age distribution of subjects in the two groups were also very different: in the group of dogs with a history of corticosteroid treatment dermatological and orthopedic problems were over-represented compared with the other group which is perhaps not surprising given the indications for these drugs; gastrointestinal conditions were more frequent within the group of dogs without a history of corticosteroid drugs, and these drugs would rarely be indicated for such problems. The effects of medical histories cannot be reliably evaluated here due to the low number of cases and although the effect of pain and discomfort on dog behaviour is an important issue (Barcelos et al., 2015, ; Camps et al., 2015) and medical problems are important sources of distress ((Mills et al., 2014; Notari, 2009), no medical problems were reliable predictors for problems relating to negative affective state. It cannot also be excluded that dogs on steroid treatment may be affected by more advanced problems that may contribute to a negative affective state. As stated above, the main finding of this investigation is that dogs presented for behaviour problems with a history of corticosteroids treatment appear to suffer more from problems associated 
1 with negative affect. The finding suggests that exposure to corticosteroids might increase dogs' 2 sensitivity to environmental and social stressors increasing the risk of problem behaviour. Given that the sample of dogs with a history of corticosteroid drugs was quite small ( $55 \mathrm{dogs})$, random effects have a greater chance of biasing the results, and so this study should not be considered definitive. Dermatological conditions were over-represented in the group of dogs with a history of corticosteroid drugs (65.5\%), compared with the other group of dogs (18.4\%) and, even though dermatological condition was not found to be a predictor for affective state, a combined effect of drugs and disease on negative affective states cannot be excluded. A matched control study with a similar result would provide stronger evidence.

It has been shown that pruritus might be exacerbated by psychological disorders in humans but also that pruritus can worsen behaviour (Shaw et al., 2007). The issue of the influence of pruritus as a main sign of dermatological conditions was investigated in dogs by Klinck et al. (2008) and they found no relationship between pruritus and aggression or anxiety, but they did find a significant increase in reactivity to potentially fearful stimuli in dogs treated with corticosteroid drugs. This is consistent with our hypothesis of an increase in negative affective states due to corticosteroid treatment.

Among dogs who had a history of corticosteroids, the co-administration of other therapies further complicates the interpretation of the results for two main reasons: multiple drug treatments might indicate that the medical problems are more severe and also other kind of medication might have psychiatric side effects (Sternbach and State, 2009; Turjanski, 2005).

Corticosteroids and age were significantly related to problems of hyperactivity. Dogs with a history of corticosteroid treatment were significantly less likely to be hyperactive, and, given the definition of hyperactivity used in this study which included excessive play behaviours, this result might be consistent with the decreased tendency to play and decreased dogs' activity levels reported in previous studies (Notari and Mills, 2011; Notari et al., 2015) although, again, young dogs might just be more prone to be hyperactive compared with older ones. Dogs between one and two years of age were much more represented in the 'no cortico' group (62.2\%) compared with those receiving corticosteroids $(29.1 \%)$ and the effect of corticosteroid might be a concomitant effect of age. This also raises the possibility that, the relationship between corticosteroid and negative affect might also be due to such age-drug association rather than an effect of corticosteroids per se. Hyperactivity problems in this study included a list of problematic behaviours like play and play biting, excessive attention seeking behaviours, jumping on people, destructiveness, and excessive excitement in different situations; all of which might be considered to reflect positive affect (reward seeking). The term does not imply a diagnosis of pathological hyperactivity associated with 
1 impaired attention as in humans beings (Blum et al., 2008; Wright et al., 2012), and a lower level of

2 activity might also be related to a lower motivation to play and seeking rewards in general.

3 In the caseload presented here, overall $16 \%$ of dogs had a history of treatment with corticosteroid 4 drugs, this is slightly higher than that reported in general veterinary practice (14.55) (O'Neill et al., 5 2012). For dermatological conditions $20 \%$ of dogs have been reported to receive a prescription of corticosteroid drugs (Hill et al., 2006) and in our caseload among those dogs with a history of dermatological conditions, corticosteroid drug prescription was even more common (40.4\%). This might again suggest that dogs on corticosteroid are more likely to show behaviour problems or that a combination of corticosteroid treatment and dermatological conditions influences problematic behaviour. However, as there was not a control group from general veterinary practice included in this study, it is not possible to establish if dogs treated with corticosteroids are over represented among subjects with behavioural problems; nonetheless these percentages indicate that the issue is an important one that requires further attention.

In this retrospective study, no specific behaviour problem was found to be linked with a history of corticosteroid drugs while in previous surveys owners reported behavioural changes in specific aspects of their dogs' behaviour (Notari and Mills, 2011; Notari et al., 2015).

Nevertheless these results deserve attention because a higher apparent tendency to be in negative affective states, a condition defined following the criteria described in the Material and Method section, might be particularly important for individual dogs that already have the propensity to show avoidance or aggressive behaviours.

Systemic glucocorticoid prescription in pet dogs seems to be determined more by the clinical experience and personal opinion of vets (O’Neill et al., 2012) and greater recognition of the widespread risk of the possible drawbacks from these drugs, including the conditions identified in this research, might contribute to improved evidence-based guidance for the therapeutic use of these drugs that minimize the risks .

\section{Conclusions}

In this study it was shown that a history of corticosteroid treatment is significantly associated with problem behaviours associated with negative affective state. Negative changes in companion dog behaviour impact not only the welfare of dogs but also the life of their owners and caregivers. Given that other studies have shown that corticosteroid drugs can bias sensitivity towards aversion in dogs making them more prone to react negatively to novel or mildly stressful situations, the current data add to the suggestion that behavioural considerations should be taken into account 
1 when corticosteroid drugs are being prescribed, in particular when this relates to dogs who show or

2 have shown behaviour problems associate with negative affect such as fear and frustration related 3 issues.

4

5 


\section{References}

A-M. Barcelos, D. S. Mills, H.Z., 2015. Clinical indicators of occult musculoskeletal pain in aggressive dogs. Vet. Rec. Open doi:10.113.

Blum, K., Chen, A.L.-C., Braverman, E.R., Comings, D.E., Chen, T.J.H., Arcuri, V., Blum, S.H., Downs, B.W., Waite, R.L., Notaro, A., Lubar, J., Williams, L., Prihoda, T.J., Palomo, T., Oscar-Berman, M., 2008. Attention-deficit-hyperactivity disorder and reward deficiency syndrome. Neuropsychiatr. Dis. Treat. 4, 893-918. doi:10.2147/NDT.S2627

Camps, T., Amat, M., Mariotti, V.M., Le Brech, S., Manteca, X., 2015. Pain-related aggression in dogs: 12 clinical cases. J. Vet. Behav. Clin. Appl. Res. 7, 99-102. doi:10.1016/j.jveb.2011.08.002

Dodman, N.H., Donnelly, R., Shuster, L., Mertens, P., Rand, W., Miczek, K., 1996. Use of fluoxetine to treat dominance aggression in dogs., Journal of the American Veterinary Medical Association.

Drozdowicz, L.B., Bostwick, J.M., 2015. Psychiatric Adverse Effects of Pediatric Corticosteroid Use. Mayo Clin. Proc. 89, 817-834. doi:10.1016/j.mayocp.2014.01.010

Fardet, L., Petersen, I., Nazareth, I., Ph, D., 2012. Suicidal behavior and severe neuropsychiatric disorders following glucocorticoid therapy in primary care. Am. J. Psychiatry 169, 491-497.

Fatjo, J., Amat, M., Mariotti, V.M., de la Torre, J.L.R., Manteca, X., 2007. Analysis of 1040 cases of canine aggression in a referral practice in Spain. J. Vet. Behav. Clin. Appl. Res. 2, 158-165.

Guy, N.C., Luescher, U.A., Dohoo, S.E., Spangler, E., Miller, J.B., Dohoo, I.R., Bate, L.A., 2001. A case series of biting dogs: Characteristics of the dogs, their behaviour, and their victims. Appl. Anim. Behav. Sci. 74, 43-57.

Hill, P.B., Lo, A., Eden, C.A.N., Huntley, S., Morey, V., Ramsey, S., Richardson, C., Smith, D.J., Sutton, C., Taylor, M.D., Thorpe, E., Tidmarsh, R., Williams, V., 2006. Survey of the prevalence, diagnosis and treatment of dermatological conditions in small animals in general practice. Vet. Rec. 158, 533-539.

Kenna, H. a., Poon, A.W., De Los Angeles, C.P., Koran, L.M., 2011. Psychiatric complications of treatment with corticosteroids: Review with case report. Psychiatry Clin. Neurosci. 65, 549-560. doi:10.1111/j.1440-1819.2011.02260.x

King, J.N., Simpson, B.S., Overall, K.L., Appleby, D., Pageat, P., Ross, C., Chaurand, J.P., Heath, S., Beata, C., Weiss, A.B., Muller, G., Paris, T., Bataille, B.G., Parker, J., Petit, S., Wren, J., 2000. Treatment of separation anxiety in dogs with clomipramine: Results from a prospective, randomized, double-blind, placebo-controlled, parallel-group, multicenter clinical trial. Appl. Anim. Behav. Sci. 67, 255-275. 
1 Klinck, M.P., Shofer, F.S., Reisner, I.R., 2008. Association of pruritus with anxiety or aggression in dogs. J.

2

3

4

5

6

7

8

9 10 Am. Vet. Med. Assoc. 233, 1105-1111.

Marder, A.R., 1991. Psychotropic drugs and behavioral therapy. Vet. Clin. North Am. Small Anim. Pract. $21,329-342$.

Mikics, É., Barsy, B., Haller, J., 2007. The effect glucocorticoids on aggressiveness in established colonies of rats. Psychoneuroendocrinology 32, 160-170.

Mills, D., Karagiannis, C., Zulch, H., 2014. Stress-its effects on health and behavior: A guide for practitioners. Vet. Clin. North Am. - Small Anim. Pract.

Notari, L., 2009. Stress in veterinary behavioural medicine, in: Horwitz, D.F., Mills, D.S. (Eds.), BSAVA Manual of Canine and Feline Behavioural Medicine. British Small Animal Veterinary Association, Gloucester, pp. 136-145.

Notari, L., Burman, O., Mills, D., 2015. Behavioural changes in dogs treated with corticosteroids. Physiol. Behav. 151, 609-616. doi:10.1016/j.physbeh.2015.08.041

Notari, L., Mills, D., 2011. Possible behavioral effects of exogenous corticosteroids on dog behavior: A preliminary investigation. J. Vet. Behav. Clin. Appl. Res. 6, 321-327.

O’Neill, D., Hendricks, A., Summers, J., Brodbelt, D., 2012. Primary care veterinary usage of systemic glucocorticoids in cats and dogs in three UK practices. J. Small Anim. Pract. 53, 217-222. doi:10.1111/j.1748-5827.2011.01190.x

Overall, K.L., 1997. Clinical Behavioral Medicine For Small Animals. Mosby, Philadelphia USA.

Overall, K.L., Love, M., 2011. Special Report Dog bites to humans - demography, epidemiology , injury , and risk. Javma 218, 1923-1934.

Pineda, S., Anzola, B., Olivares, A., Ibáñez, M., 2014. Fluoxetine combined with clorazepate dipotassium and behaviour modification for treatment of anxiety-related disorders in dogs. Vet. J. 199, 387-391.

Shaw, R.J., Dayal, S., Good, J., Bruckner, A.L., Joshi, S. V, 2007. Psychiatric medications for the treatment of pruritus. Psychosom. Med. 69, 970-8. doi:10.1097/PSY.0b013e3181572799

Sirois, F., 2003. Steroid psychosis: A review. Gen. Hosp. Psychiatry 25, 27-33.

Sternbach, H., State, R., 2009. Antibiotics: Neuropsychiatric Effects and Psychotropic Interactions.

Turjanski, N., 2005. Psychiatric side-effects of medications: recent developments. Adv. Psychiatr. Treat.

Ularntinon, S., Tzuang, D., Dahl, G., Shaw, R.J., 2010. Concurrent treatment of steroid-related mood and psychotic symptoms with risperidone. Pediatrics 125, e1241-e1245. doi:10.1542/peds.2009-1815 
1

2

3

4

5

6

7

8

9

10

11

12

13

14

15

16

17

18

19

20

21

22

23

24

25

26

27

28

29

30

31

32

33

34

35

36

37

38

39

40

41

42

43

44

45

46

47

48

49

50

51

52

53

54

55

56

57

58

59

60

1 Warrington, T.P., Bostwick, J.M., 2006. Psychiatric Adverse Effects of Corticosteroids. Mayo Clin. Proc.

2 Wright, H.F., Mills, D.S., Pollux, P.M.J., 2012. Behavioural and physiological correlates of impulsivity in

3 the domestic dog (Canis familiaris). Physiol. Behav. 105, 676-82. doi:10.1016/j.physbeh.2011.09.019

4

5 
1

2

3

4

5

7

8

9

10

11

12

13

14

15

16

17

18

19

20

21

22

23

24

25

26

27

28

29

30

31

32

33

34

35

36

37

38

39

40

41

42

43

44

45

46

47

48

49

50

51

52

53

54

55

56

57

58

59

60

https://mc.manuscriptcentral.com/vetrec 